\title{
CLINICOPATHOLOGICAL STUDY OF CERVICAL LYMPHADENOPATHY
}

\author{
Sunil Kumar Singh Bhadouriya ${ }^{1}$, H. M. Kansal'2, Rohit Saxena ${ }^{3}$, Vivek Kumar Pathak ${ }^{4}$, Sanjeev Kumar Awasthi ${ }^{5}$ \\ ${ }^{1}$ Assistant Professor, Department of ENT, School of Medical Sciences and Research, Greater Noida. \\ ${ }^{2}$ Associate Professor, Department of TB and Chest, School of Medical Sciences and Research, Greater Noida. \\ 3 Professor, Department of ENT, School of Medical Sciences and Research, Greater Noida. \\ ${ }^{4}$ Senior Resident, Department of ENT, School of Medical Sciences and Research, Greater Noida. \\ 5 Professor, Department of ENT, School of Medical Sciences and Research, Greater Noida.
}

\section{ABSTRACT}

\section{BACKGROUND}

Neck is the most common site of peripheral lymph node enlargement and is very often encountered in otolaryngology outpatient department.

\section{AIMS}

This study was done to identify the aetiology and clinicopathological correlation of cervical lymphadenopathy.

\section{METHODS AND MATERIALS}

This study was done in patients presenting with cervical lymphadenopathy in the Otolaryngology and TB and Chest Outpatient Department of School of Medical Sciences and Research, Greater Noida, India, between December 2013 and November 2014.74 patients who underwent fine needle aspiration cytology of cervical lymph nodes were reviewed in relation to their clinical and demographic profiles.

\section{STATISTICAL ANALYSIS}

Data was collected using a proforma and data collected included patients demographics. The data obtained underwent standard statistical analysis.

\section{RESULTS}

In the cytology and histopathology, reactive nonspecific lymphadenitis (38 cases out of 74 cases, $51.35 \%$ ) was the most common diagnosis. Tuberculosis accounted for 23 cases out of 74 cases of cervical lymph node enlargement. Among the metastatic neck nodes, squamous cell carcinoma was most prevalent. The commonest age group affected was 21-30 years. Constitutional symptoms were absent in most of patients. Upper deep jugular group were the most commonly involved lymph node group. All the patients with cervical tubercular lymphadenopathy were treated with short course daily chemotherapy for six months. Surgery was not needed in majority of patients except in few cases where excision biopsy was performed.

\section{CONCLUSION}

This study highlights the role of fine needle aspiration cytology in diagnosis and management of cervical lymphadenopathy. Knowledge about the clinical and demographic profile of cervical lymphadenopathy will help the otolaryngologists to detect the cases early for management.

\section{KEYWORDS}

Fine Needle Aspiration Cytology, Biopsy, Histopathological Examination, Cervical Lymphadenopathy, Lymphoma.

HOW TO CITE THIS ARTICLE: Bhadouriya SKS, Kansal HM, Saxena R, et al. Clinicopathological study of cervical lymphadenopathy. J. Evolution Med. Dent. Sci. 2016;5(66):4730-4734, DOI: 10.14260/jemds/2016/1078

\section{INTRODUCTION}

Cervical lymphadenopathy is a common clinical problem and frequently seen in children. ${ }^{1}$ One of the commonest presenting complaints of patient in ENT OPD is cervical lymphadenopathy that is encountered by ENT specialists in day-to-day practice. Cervical lymphadenopathy is defined as cervical lymph node tissue measuring more than $1 \mathrm{~cm}$ in diameter. ${ }^{2-3}$ Cervical region is the most common site for lymphadenopathy. 4 Aetiology maybe due to simple inflammation, tuberculosis, malignancies, autoimmune diseases, iatrogenic causes, and miscellaneous conditions. ${ }^{5}$

Financial or Other, Competing Interest: None.

Submission 13-07-2016, Peer Review 06-08-2016,

Acceptance 12-08-2016, Published 18-08-2016.

Corresponding Author:

Dr. Sunil Kumar Singh Bhadouriya,

\#402 NSQ Campus, Greater Noida,

Uttar Pradesh, India.

E-mail: drsunil7121@gmail.com

DOI: $10.14260 /$ jemds/2016/1078
The most common cause is reactive hyperplasia from an infectious process. History and thorough clinical examination provide important clues to the underlying aetiology. Tuberculosis is one of the major public health problems the world is facing. Tuberculosis is still a common cause of cervical lymphadenopathy in many developing countries. Cervical tubercular lymphadenopathy is the most common extrapulmonary manifestation of tuberculosis. Tuberculosis is responsible for up to $43 \%$ of peripheral lymphadenopathy in developing world. 6 Cervical tubercular lymphadenopathy most commonly affects children and young adults, but can occur at any age. 38-45\% of normal children have palpable cervical lymph nodes. 7 90\% of children aged between $4-8$ years have palpable cervical lymph nodes. ${ }^{8}$ The jugulodigastric nodes are most commonly affected. In approximately $80 \%$ of cases, the tubercular process is limited to the clinically affected group of lymph nodes, but a primary focus in lungs must always be suspected and investigated. ${ }^{9}$ 
Fine Needle Aspiration Cytology (FNAC) is one of the simple, safe, reliable, quick, less expensive, and basic diagnostic procedure. Fine needle aspiration cytology, biopsy, and histopathological examination still have significant role for diagnosing the aetiology of cervical lymphadenopathy. Use of fine needle aspiration cytology is not always used as a routine diagnostic procedure in children. There is a need of biopsy with histopathological examination if FNAC is inconclusive.

\section{MATERIALS AND METHODS \\ Study Design}

This retrospective study was carried out among 74 patients of cervical lymphadenopathy. The study was conducted at ENT and TB Chest OPD of Sharda Hospital (SMS and R), Gr. Noida, (U.P), India, from December 2013 to November 2014. FNAC and histopathological examination were performed in the Department of Pathology. All relevant information was recorded on a prescribed proforma.

\section{Study Population: Inclusion and Exclusion Criteria}

Patients of all age group with enlarged neck nodes of more than two weeks duration were included for the study. Exclusion criteria include neck swelling other than lymph node origin and patients with enlarged neck nodes of less than two weeks duration.

\section{METHODOLOGY}

A detailed clinical history was taken and a note was made regarding age, sex, constitutional symptoms, duration of symptoms, and history of contact with tuberculosis patients. A complete physical examination was carried out. Detailed ENT and head and neck examination was done. In local examination, importance was given to the site, size, number, laterality, consistency, mobility, and involvement of other lymph nodes. An attempt was made to find out primary tumour in cases of neck secondaries. Routine investigations (Hb\%, TLC, DLC, ESR, Chest X-Ray) were done in each and every case. Total 79 patients of all age group were subjected to FNAC, however, material was inadequate in 5 cases and they were excluded from this study. So, only 74 cases were available for study. In this study, FNAC was found inconclusive in some cases due to unsatisfactory smears. These unsatisfactory smears were found because of poor preparation and/or staining. Histopathological examination was done in cases where repeated FNAC was found non-diagnostic. The primary site was searched for and biopsy was taken from the primary site for histopathological examination in neck secondaries cases. In addition to above investigations, Mantoux test and sputum for AFB were done in appropriate cases. Endoscopy and radiological investigations were carried out in relevant cases. Medical treatment was instituted for conditions like tubercular lymphadenitis and reactive lymphadenitis. For oncologic surgeries, radiotherapy and chemotherapy patients were referred to higher centre. All patients were asked to attend ENT and TB Chest OPD for followup.

\section{Statistical Study}

Data was collected using a proforma and data collected included patients demographics. The data obtained underwent standard statistical analysis. Data were shown as mean \pm standard deviation and number of cases.

\section{Ethical Aspects}

The study protocol was approved by Institute Ethical Committee. Informed and written consent were taken from all the patients included in the study. Patients without consent were excluded from the study.

\section{RESULTS}

The present study includes 74 patients, both outpatients as well as inpatients at the ENT and TB Chest Department of School of Medical Sciences and Research for a period of one year. In the present study, 74 cases were evaluated for cervical lymph node enlargement. All cases were taken for fine needle aspiration cytology. Maximum number of cases 19 (25.7\%) were between 21-30 years of age.

Out of the 74 cases studied, 44 cases were males and 30 cases females. Male-to-female ratio was 1.47:1. Figure 1 shows that males are more often affected than females.

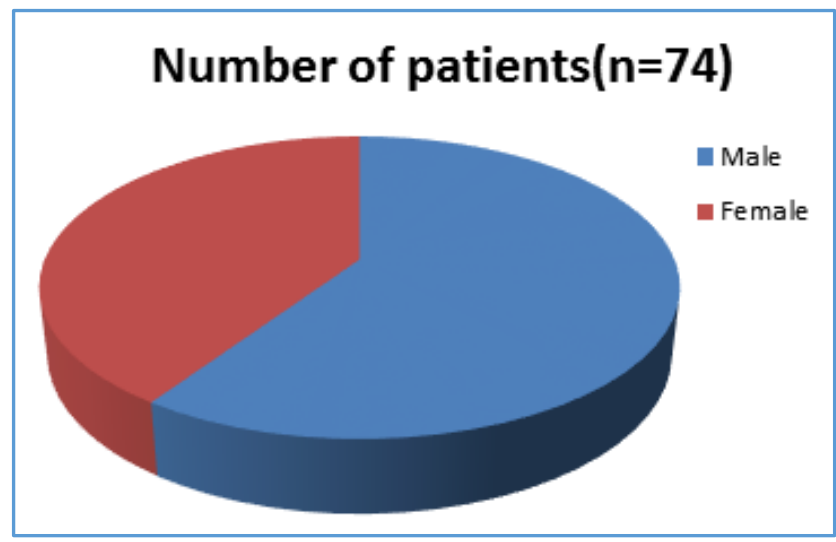

Fig. 1: Gender Distribution of Patients

In the present study, it was observed that maximum number of cases $19(25.7 \%)$ were between 21-30 years of age. Next common age group involved was between 11-20 years (14 cases, $18.9 \%$ ). Only seven cases were found to be above 60 years. Lowest age recorded was 2 years of age and highest 80 years of age. Figure 2 is showing age distribution of patients.

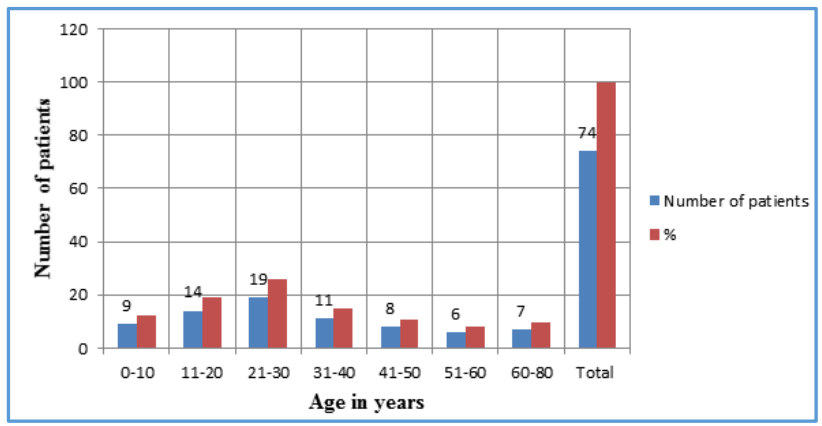

Mean \pm SD $30.094 \pm 18.731$

Fig. 2: Age Distribution of Patients

Out of 74 cases, 38 cases (51.35\%) were confirmed as reactive and chronic nonspecific lymphadenitis, 23 cases (31.08\%) as tubercular lymphadenitis, 11 cases $(14.86 \%)$ as secondaries and 2 cases $(2.70 \%)$ as lymphoma. Thus, among the lesions affecting cervical lymph nodes, reactive nonspecific aetiology was the most common. Causes of cervical lymphadenopathy can be classified as neoplastic and nonneoplastic lesions. Among the neoplastic causes, neck 
secondaries had the maximum number of cases (11 cases) followed by lymphoma. Out of the 11 cases of malignant secondaries, 5 were from the larynx, 4 from the oropharynx and hypopharynx. The remaining 2 cases had unknown primary. Partial lymph node involvement might be the cause of false negative FNAC in neck secondaries cases and histopathological examination was required in these cases. Many times, FNAC may reveal only necrosis, which on histopathology revealed malignancy. In suspicious situations, biopsy was taken for histopathological examination. Table 1 shows results of FNAC/histopathological examination performed in 74 cases. Figure 3 shows Langerhans giant cells surrounded by lymphocytes on histopathology. Figure 4 shows central amorphous substance with destruction of cells suggestive of caseous necrosis on histopathology.

\begin{tabular}{|c|c|c|}
\hline $\begin{array}{c}\text { FNAC/Histopathological } \\
\text { Findings }\end{array}$ & $\begin{array}{c}\text { Number of } \\
\text { Patients } \\
\text { (n=74) }\end{array}$ & \% \\
\hline Reactive nonspecific & 38 & 51.35 \\
\hline Tubercular & 23 & 31.08 \\
\hline Lymphoma & 02 & 02.70 \\
\hline Metastatic & 11 & 14.86 \\
\hline Table 1: Distribution of FNAC/Histopathological \\
Findings of Patients \\
\hline
\end{tabular}

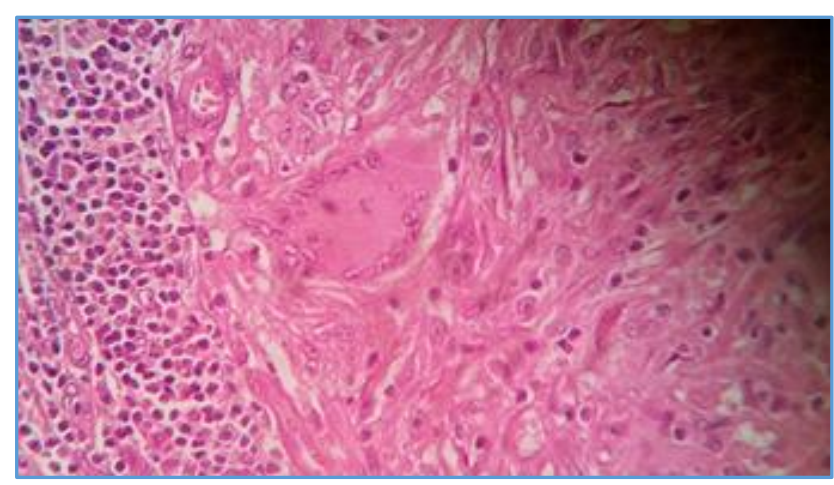

Fig. 3: Histopathology of Tuberculosis of Cervical Lymph Node showing Langerhans Giant Cells Surrounded by Lymphocytes (40 x Magnifications)

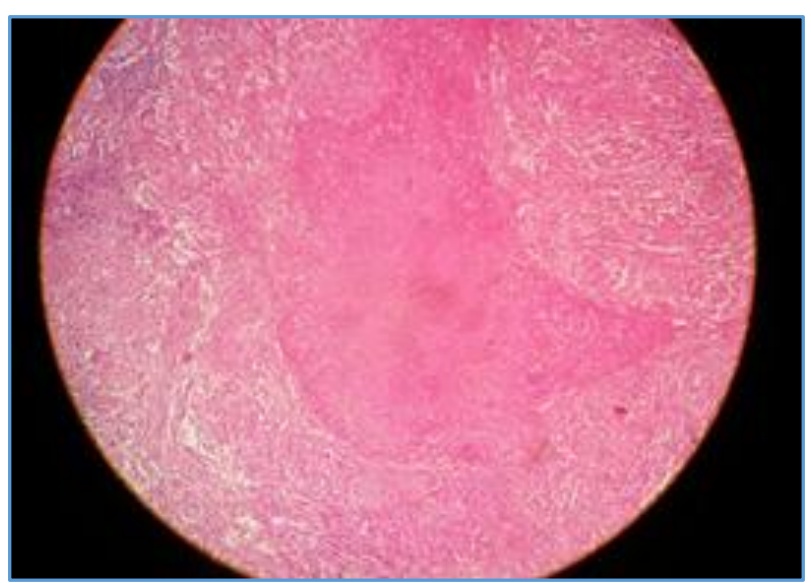

Fig. 4: Histopathology of Tuberculosis of Cervical Lymph Node showing Central Amorphous Substance with Destruction of Cells Suggestive of Caseous Necrosis (10 x Magnifications)

The constitutional symptoms considered were fever, weight loss, malaise, loss of appetite, dysphagia, hoarseness of voice, and cough. In the present study, majority of cases of tubercular lymphadenitis and neck secondaries did not have constitutional symptoms. 8 cases out of 23 cases (34.8) of tubercular aetiology and 3 cases $(27.3 \%)$ out of 11 cases of neck secondaries showed presence of constitutional symptoms. 15 cases out of 38 cases of reactive lymphadenitis showed presence of symptoms. 1 case out of 2 cases of lymphoma showed presence of symptoms. In the present study, fever was the most common symptom seen followed by malaise. Table 2 is showing distribution of constitutional symptoms.

\begin{tabular}{|c|c|c|}
\hline $\begin{array}{c}\text { Constitutional } \\
\text { Symptoms }\end{array}$ & $\begin{array}{c}\text { Number of } \\
\text { Patients (n=74) }\end{array}$ & $\mathbf{\%}$ \\
\hline Present & 27 & 36.5 \\
\hline Nil & 47 & 63.5 \\
\hline Table 2: Distribution of Constitutional Symptoms \\
\hline
\end{tabular}

Only few cases with tubercular lymphadenitis had a positive history of contact with tuberculosis. Only 5 cases $(21.7 \%)$ out of 23 cases had a positive history. Table 3 is showing history of contact with tuberculosis in tubercular lymphadenitis.

\begin{tabular}{|c|c|c|}
\hline $\begin{array}{c}\text { H/O Contact } \\
\text { with TB }\end{array}$ & $\begin{array}{c}\text { Number of } \\
\text { Patients }\end{array}$ & $\%$ \\
\hline Negative & 18 & 78.3 \\
\hline Positive & 5 & 21.7 \\
\hline Total & $\mathbf{2 3}$ & $\mathbf{1 0 0}$ \\
\hline Table 3: History of Contact with Tuberculosis in Cervical \\
Tubercular Lymphadenopathy \\
\hline
\end{tabular}

In the present study, it was observed that upper deep jugular group was the commonest lymph node group to get involved followed by posterior triangle group. About $20 \%$ cases had more than one site involvement. 2 cases of lymphoma had more than one site involvement.

In the present study, it was observed that majority of nodes affected were less than $3 \mathrm{~cm}$ in size (86.5\%). The remaining were equal or more than $3 \mathrm{~cm}(13.5 \%)$. Table 4 is showing size of lymph nodes in 74 cases of cervical lymphadenopathy.

\begin{tabular}{|c|c|c|}
\hline $\begin{array}{c}\text { Size in } \\
\text { Centimeters }\end{array}$ & $\begin{array}{c}\text { Numbers of } \\
\text { Patients }\end{array}$ & $\%$ \\
\hline Less than $3 \mathrm{~cm}$ & 64 & 86.5 \\
\hline More than $3 \mathrm{~cm}$ & 10 & 13.5 \\
\hline Total & 74 & 100 \\
\hline
\end{tabular}

Unilateral involvement of lymph nodes was observed to be more common. It was seen in 63 cases out of 74 cases (85.1\%). The remaining (14.9\%) cases had bilateral involvement. Table 5 is showing unilateral/bilateral involvement of lymph nodes in cervical lymphadenopathy.

\begin{tabular}{|c|c|c|}
\hline $\begin{array}{l}\text { Lymph Node } \\
\text { Involvement }\end{array}$ & $\begin{array}{l}\text { Number of } \\
\text { Patients }\end{array}$ & $\%$ \\
\hline Unilateral & 63 & 85.1 \\
\hline Bilateral & 11 & 14.9 \\
\hline Total & 74 & 100 \\
\hline \multicolumn{3}{|c|}{$\begin{array}{c}\text { Table 5: Unilateral/Bilateral Involvement of Lymph } \\
\text { Nodes in Cervical Lymphadenopathy }\end{array}$} \\
\hline
\end{tabular}


In this study, 60 cases (81.1\%) had single node involvement while 14 cases (18.9\%) showed multiple node involvement.

Matting of lymph nodes was observed in 5 cases $(21.7 \%)$ while 18 cases out of 23 cases of tuberculosis showed discrete lymph nodes.

11 cases (47.8\%) out of 23 cases of tuberculosis had caseation in lymph nodes while 12 cases $(52.2 \%)$ had noncaseated lymph nodes.

4 cases $(17.4 \%)$ showed lung involvement on x-ray chest along with tubercular lymphadenitis while 19 cases (82.6\%) were negative. Table 6 is showing chest $\mathrm{x}$-ray positivity in cervical tubercular lymphadenopathy.

\begin{tabular}{|c|c|c|}
\hline Chest X-Ray & $\begin{array}{c}\text { Number of } \\
\text { Patients (n=23) }\end{array}$ & $\mathbf{\%}$ \\
\hline Positive & 4 & 17.4 \\
\hline Negative & 19 & 82.6 \\
\hline Total & $\mathbf{2 3}$ & $\mathbf{1 0 0}$ \\
\hline Table 6: Chest X-Ray Positivity in Cervical Tubercular \\
Lymphadenopathy \\
\hline
\end{tabular}

24 cases $(32.4 \%)$ out of 74 cases studied had a haemoglobin level of less than $10 \mathrm{~g} \%$ while 50 cases $(67.6 \%)$ had haemoglobin of more than $10 \mathrm{~g} \%$.

13 cases $(56.5 \%)$ of tubercular lymphadenitis had an ESR of more than $20 \mathrm{~mm} / \mathrm{hr}$ while 10 cases had an ESR of less than $20 \mathrm{~mm} / \mathrm{hr}$. Table 7 is showing ESR level in cervical tubercular lymphadenopathy.

\begin{tabular}{|c|c|c|}
\hline ESR in mm/hr & $\begin{array}{c}\text { Number of } \\
\text { Patients (n=23) }\end{array}$ & \% \\
\hline Less than 20 & 10 & 43.5 \\
\hline More than 20 & 13 & 56.5 \\
\hline \multicolumn{2}{|c|}{ Table 7: ESR Level in Cervical Tubercular } \\
Lymphadenopathy \\
\hline
\end{tabular}

\section{DISCUSSION}

Commonest age group affected in our study was 21 years to 30 years (19 cases, $25.7 \%$ ) followed by 11 years to 20 years (14 cases, $18.9 \%$ ) consistent with the study conducted by Subrahmanyam M. ${ }^{10}$ Only 7 cases were found to be above 60 years. Lowest age recorded was 2 years of age and highest 80 years of age with an overall mean age of $30.094 \pm 18.731$ years.

In our present study, incidence in males (59.5\%) was more than that in females $(40.5 \%)$ with male-to-female ratio of 1.469:1. Mishra SD et al ${ }^{11}$ in their study observed slightly higher incidence in males with male-to-female ratio of 1.1:1. Moore et $\mathrm{al}^{3}$ found male preponderance with male-to-female ratio of 3:1. The results in this study are similar to other studies.

The constitutional symptoms considered are fever, malaise, weight loss, loss of appetite, change in voice, cough, haemoptysis, and difficulty in swallowing. In the present study, most of the cases did not have constitutional symptoms. 8 cases out of 23 cases (34.8) of tubercular aetiology and 3 cases $(27.3 \%)$ out of 11 cases of neck secondaries showed presence of constitutional symptoms. 15 cases out of 38 cases of reactive lymphadenitis showed presence of symptoms. In the present study, fever was the most common symptom seen followed by malaise. Patel and Mehta observed weight loss in $77 \%$ and fever in $73 \%$ of their patients. ${ }^{12}$ Similarly Dandapat et al also observed weight loss in $85 \%$ and fever in $40 \%$ of their patients. ${ }^{4}$ Our observation differs significantly from others.

The most common group of lymph nodes affected in our study was that of the upper deep jugular and jugulodigastric lymph nodes followed by posterior triangle group. These results are similar to the results of Dandapat et al $^{4}$ In a study by Kheiry and Ahmed, the most affected nodes were in the posterior triangle. 13

In the present study, out of 74 cases, 38 cases (51.35\%) were confirmed as reactive and chronic nonspecific lymphadenitis, 23 cases $(31.08 \%)$ as tubercular lymphadenitis, 11 cases (14.86\%) as secondaries and 2 cases $(2.70 \%)$ as lymphoma. Thus, among the lesions affecting cervical lymph nodes, reactive nonspecific aetiology was the most common. The study done by Maria et al 6 reported reactive hyperplasia in $70 \%$ cases, granulomatous lesion in $14 \%$ cases, and malignancy in $12 \%$ cases. These results are similar to our results. In a study Jha et $\mathrm{al}^{14}$ had reported tuberculosis as the most common cause of cervical lymphadenopathy. In a study by Narang et $\mathrm{al}^{2}$ the prevalence of tubercular lymphadenopathy in children is approximately 4.4 cases per 1000 .

Fine needle aspiration cytology is a well-established routine diagnostic procedure in all cases of cervical lymphadenopathy. Few cases were subjected to biopsy and histopathological examination when their fine needle aspiration cytology reports were found inconclusive. In the developing countries, the presence of granulomatous lesion on fine needle aspiration cytology is highly suggestive of tuberculosis. In this study, we found it to be a very useful diagnostic tool to identify the aetiology of cervical lymphadenopathy. It eliminates the need for excisional biopsy in most patients. Similar views have been shared by the others.

In this study, we successfully treated most of the patients. All the patients with tubercular lymphadenopathy were treated with short course daily chemotherapy for six months. Surgery was rarely required. This experience is similar to experience of Patel and Mehta. ${ }^{12}$

\section{CONCLUSION}

Cervical lymphadenopathy is a common clinical problem in cervical region. It is evident in this study that reactive hyperplasia is the diagnosis in most cases. Tuberculosis is common disease affecting lymph nodes in cervical region. Cervical lymphadenopathy is more common in younger patients (0-20 years). Constitutional symptoms were not present in most of patients. Patients need detailed evaluation with investigations like chest $\mathrm{x}$-ray, Mantoux test, FNAC, and histopathological examination. FNAC is a simple, safe, cost effective, well tolerated, and minimally invasive test with no reported complications. It is reliable test in diagnosis of cervical lymphadenopathy especially when used in combination with other tests. It is seen in our study that majority of cervical lymphadenopathy are of benign nature. Whenever we suspect malignancy we should always recommend biopsy and histopathological examination. Most patients can be managed conservatively and surgery is rarely required. A team work with close cooperation among otorhinolaryngologists, TB and Chest physician, and pathologist is essential for making proper diagnosis and management of cervical lymphadenopathy. 


\section{ACKNOWLEDGEMENTS}

Thanks to colleagues and staff of Department of Pathology for their support.

\section{REFERENCES}

1. Papadopouli E, Michaillidi E, Paspalki P, et al. Cervical lymphadenopathy in childhood epidemiology and management. Paediatr Haematol Oncol 2009;26(6): 454-60.

2. Narang $P$, Narang $R$, Narang $R$, et al. Prevalence of tuberculous lymphadenitis in children in Wardha district, Maharashtra State, India. Int J Tuberc Lung Dis 2005;9(2):188-94.

3. Moore SW, Schneider JW, Schaaf HS. Diagnostic aspects of cervical lymphadenopathy in children in the developing world: a study of 1,877 surgical specimens. Paediat Surg Int 2003;19(4):240-4.

4. Dandapat MC, Mishra BM, Das SP, et al. Peripheral lymph node tuberculosis: a review of 80 cases. Br J Surg 1990;77(8):911-2.

5. Bazemore AW, Smucker DR. Lymphadenopathy and malignancy. Am Fam Physician 2002;66(11):2103-11.

6. Ingolfsdottir M, Balle V, Christoffer HH. Evaluation of cervical lymphadenopathy in children: advantages and drawbacks of diagnostic methods. Dan Med J 2013; 60(8): $1-3$.
7. Larsson LO, Bentzon MW, Kelly BK, et al. Palpable lymph nodes of the neck in Swedish school children. Acta Paediatrica 1994;83(10):1091-4.

8. Park YW. Evaluation of neck masses in children. Am Family Physician 1995;51(8):1904-12.

9. Russell RCG, Williams NS, Christopher JKB, eds. Bailey and Love's Short Practice of Surgery. 24th edn. International Students edition, London: Arnold 2004:p. 773.

10. Subrahmanyam M. Role of surgery and chemotherapy for peripheral lymph node tuberculosis. $\mathrm{Br} \mathrm{J}$ Surg 1993;80(12):1547-8.

11. Mishra SD, Garg BK. Cervical lymphadenitis in children: a study of 137 cases. Indian paediatr 1972;9(12):812-5.

12. Patel RV, Mehta RT. Short-term chemotherapy in tuberculous lymphadenitis. Indian Journal of Surgery 1987;49:336-41.

13. Kheiry J, Ahmed ME. Cervical lymphadenopathy in Khartoum. Journal of Tropical Medicine and Hygiene 1992;95(6):416-9.

14. Jha BC, Dass A, Nagarkar NM, et al. Cervical tuberculous lymphadenopathy: changing clinical pattern and concepts in management. Postgrad Med J 2001;77(905):185-7. 